\title{
Clostridium difficile-associated diarrhea in 200 Canadian children
}

\author{
Véronique Morinville $\mathrm{MD}^{1}$, Jane McDonald MD FRCPC ${ }^{2}$
}

\begin{abstract}
V Morinville, J McDonald. Clostridium difficile-associated diarrhea in 200 Canadian children. Can J Gastroenterol 2005;19(8):497-501.
\end{abstract}

OBJECTIVE: Clostridium difficile-associated diarrhea is a major problem in adults. The present study was conducted to assess risk factors and outcomes in children with $\mathrm{C}$ difficile-associated diarrhea.

METHODS: Laboratory records at a university-affiliated pediatric hospital were reviewed for all $\mathrm{C}$ difficile toxin-positive stools (cell culture cytotoxin assay) between 2000 and 2003. Charts on identified patients were reviewed.

RESULTS: Two hundred patients with a diagnosis of $\mathrm{C}$ difficileassociated diarrhea were identified between February 2000 and November 2003. There were 107 males and 93 females (mean age 5.4 years; median age 2.6 years). Underlying factors were identified in 19\% (12 patients underwent chemotherapy; seven patients had Crohn's disease; six were transplantation recipients; seven an immunodeficiency; four with Hirschsprung disease; two diagnoses of 'other'). Of the 200 identified patients, 149 (74.5\%) had documentation of antibiotics in the previous two months (32 penicillins; 38 cephalosporins; three clindamycin, nine other single-agent, 59 multiple; eight not specified), and 111 (55.5\%) had been hospitalized in the previous month. The symptoms of $\mathrm{C}$ difficile-associated diarrhea included bloody stools in $12.5 \%$ and frequent watery stools in $79 \%$. Hospitalization was required in 27 of 116 outpatients; stay was prolonged in seven of the 84 patients already hospitalized. Fifty-five per cent received metronidazole, $34 \%$ were not treated, and treatment data were not available for the remainder. Recurrence occurred in $31 \%$ of those treated and retreatment consisted of vancomycin (15\%), probiotics $(15 \%)$ and cholestyramine $(6 \%)$. No colectomies were required but two deaths occurred.

CONCLUSIONS: The majority of pediatric patients developing symptomatic $\mathrm{C}$ difficile-associated diarrhea had antibiotic exposure or hospitalization within the previous one to two months. This is higher than previously reported. One-third had spontaneous symptom resolution. For those treated, recurrence rates were high. Mortality was significantly lower than described in adults, in agreement with prior literature.

\section{Diarrhée à Clostridium difficile chez 200 enfants au Canada}

CONTEXTE : La diarrhée à Clostridium difficile constitue un problème de santé important chez les adultes. La présente étude avait pour but d'évaluer les facteurs de risque de la diarrhée à C. difficile chez les enfants, ainsi que les résultats.

MÉTHODE : Nous avons passé en revue les archives de laboratoire, dans un centre hospitalier universitaire pour enfants, à la recherche de toutes les analyses de selles effectuées entre 2000 et 2003, qui s'étaient révélées positives à l'égard de la toxine de C. difficile (épreuve de cytotoxicité en culture cellulaire). Les dossiers des patients repérés ont été examinés.

RÉSULTATS : Deux cents cas de diarrhée à C. difficile ont été diagnostiqués entre février 2000 et novembre 2003 (107 garçons et 93 filles [âge moyen : 5,4 ans; âge médian : 2,6 ans]). Des facteurs sous-jacents ont été relevés dans $19 \%$ des cas (chimiothérapie : 12; maladie de Crohn : 7; transplantation : 6; immunodéficience : 7; maladie de Hirschsprung : 4 autres : 2). Sur les 200 patients repérés, 149 (74,5\%) avaient fait une utilisation documentée d'antibiotiques au cours des deux mois précédents (pénicilline : 32; céphalosporine : 38; clindamycine : 3; autre monoantibiothérapie : 9; polyantibiothérapie : 59 ; non précisés : 8) et $111(55,5 \%)$ avaient été hospitalisés au cours du mois précédent. Les symptômes de la diarrhée à C. difficile étaient des selles sanguinolentes (12,5\%) et des selles aqueuses, fréquentes (79\%). Il a été nécessaire d'hospitaliser 27 enfants sur 116 et de prolonger le séjour de 7 patients sur 84 à l'hôpital. Cinquante-cinq pour cent des enfants malades ont reçu du métronidazole et, 34 \% n'ont pas été traités; quant aux autres, il n'y avait pas de données sur le traitement. La maladie est réapparue chez $31 \%$ des enfants traités, et le traitement comprenait alors de la vancomycine $(15 \%)$, des probiotiques $(15 \%)$ ou de la cholestyramine $(6 \%)$. Il n'a pas été nécessaire de procéder à des colectomies, mais il y a eu deux décès.

CONCLUSIONS : La plupart des enfants qui ont souffert de diarrhée symptomatique à $\mathrm{C}$. difficile avaient fait usage d'antibiotiques ou avaient été hospitalisés au cours du mois ou des deux mois précédents. Il s'agit là d'une corrélation encore plus forte que celle qui avait été signalée antérieurement. Les symptômes sont disparus spontanément dans un tiers des cas. Par contre, le taux de réapparition de la maladie était élevé chez les patients traités. Enfin, la mortalité était significativement plus faible chez les enfants que chez les adultes, résultat qui confirme la tendance relevée dans la documentation.

Key Words: Clostridium difficile; Diarrhea; Morbidity; Pediatrics

Clostridium difficile is a ubiquitous, spore-forming anaerobic bacterium found in the environment and known to cause gastrointestinal infections in humans. $\mathrm{C}$ difficile proliferates in the human gut and secretes cytotoxins $\mathrm{A}$ and $\mathrm{B}$, which adhere to the colonic mucosa and may lead to a variety of symptoms including abdominal pain, nonspecific mild diarrhea, more profuse watery diarrhea, protein-losing enteropathy, colitis and toxic megacolon, which can culminate in intestinal perforation and/or death.

${ }^{1}$ Division of Pediatric Gastroenterology and Nutrition; ${ }^{2}$ Division of Pediatric Infectious Diseases, Montreal Children's Hospital, McGill University Health Centre, Montreal, Quebec

Correspondence: Dr Jane McDonald, Division of Pediatric Infectious Diseases, Room C-1342, Montreal Children's Hospital, McGill University Health Centre, 2300 Tupper Street, Montreal, Quebec H3H 1P3. Telephone 514-412-4313, fax 514-412-4354,

e-mail jane.mcdonald@muhc.mcgill.ca

Received for publication April 12, 2005. Accepted April 19, 2005 
Literature regarding risk factors for symptomatic $\mathrm{C}$ difficile infection is predominantly adult-based (1-6). Factors predisposing to symptomatic $\mathrm{C}$ difficile infection include increasing age and severity of underlying illness, prior antimicrobial therapy, hospitalizations, intensive care unit stay, presence of nasogastric tube and other nonsurgical gastrointestinal procedures, use of antiperistaltic drugs, acid antisecretory medications and certain chemotherapeutic agents. For many risk factors, it is unclear whether they act independently or are simply common confounders in sick hospitalized adults. Recent antibiotic use (within eight weeks) remains a key exposure risk, and is found in virtually all adults who develop symptomatic $\mathrm{C}$ difficile. The most commonly reported antibiotics are penicillins, clindamycin and cephalosporins. Lately, proton pump inhibitors have been implicated as an independent risk factor for symptomatic disease, probably related to their potency in reducing gastric acidity in conjunction with their now widespread use $(7,8)$. There has been mounting concern about an increasing number and severity of $\mathrm{C}$ difficile cases in recent years $(3,5)$.

Therapeutic options include not only metronidazole and oral vancomycin but, for recurrent and nonresponsive cases, probiotics such as Lactobacillus GG and Saccharomyces boulardii, toxin-binding agents such as cholestyramine, intravenous immunoglobulin, prolonged tapering regimens of vancomycin and stool enemas (6,9-15).

The pediatric literature regarding $\mathrm{C}$ difficile infections is sparse. Suspected risk factors for infection include recent exposure to antibiotics, recent hospitalization, young age, chemotherapy, transplant recipient, an abnormal gastrointestinal tract (inflammatory bowel disease, Hirschsprung disease, etc) and immunodeficiency $(6,16-22)$. There are no pediatric studies investigating the role of acid-blockade in the increasing prevalence of disease.

A complicating factor in the study of pediatric $\mathrm{C}$ difficile is the high rate of asymptomatic carriage. Whereas less than 5\% of outpatient adults are found to carry $\mathrm{C}$ difficile, the rate is much higher in children (6). In general, age is inversely correlated with colonization rates. $\mathrm{C}$ difficile isolation rates have been reported to be $0 \%$ to $61 \%$ in infants younger than one month, $3 \%$ to $33 \%$ in those aged one to 23 months, and $8.1 \%$ to $8.3 \%$ in children older than two years of age (18). Bottle-fed children have higher colonization rates than breastfed infants while hospitalized children, especially those in neonatal care units, are more likely to carry $\mathrm{C}$ difficile than their outpatient counterparts (23-25).

The present study was conducted to examine the epidemiological factors associated with $\mathrm{C}$ difficile infections in children, evaluate risk factors for persistent and recurrent infections, and explore the spectrum of treatment options used in a pediatric population.

\section{METHODS}

A retrospective chart review was conducted at a university-affiliated tertiary care pediatric hospital in Montreal, Quebec. Virology records were reviewed for positive $\mathrm{C}$ difficile cytotoxin results. A chronological backward search for the last 200 consecutive children with positive results was performed. Medical records of these patients were reviewed. Test samples originated from outpatients, the emergency department and from inpatient wards. The hospital had a busy emergency room, an active hematology/oncology program including bone marrow transplantation, solid organ transplants, neonatal and pediatric intensive care units, and general inpatient medical and surgical wards.

In all patients, $\mathrm{C}$ difficile was detected by cytotoxin B assay in cell culture.

Patient characteristics were recorded. Children younger than one year of age were reviewed not only as part of the overall group but also separately. Nosocomial infection was defined as $\mathrm{C}$ difficile occurring within one month of hospitalization or infection occurring after hospitalization greater than $48 \mathrm{~h}$.

Characteristics of disease course were recorded. The main outcomes of interest included the need for antibiotic therapy versus spontaneous resolution of disease, treatment failures and serious adverse outcomes.

\section{RESULTS}

Two hundred patients were identified from February 12, 2000, to November 30, 2003. Patients who had more than one positive result during this period were only counted once. Results presented are based on available information from all 200 patient hospital records.

Patient characteristics are displayed in Table 1 . There were 107 males and 93 females with a mean age of 5.4 years (range 0.1 to 18.7 years, median age 2.6 years). There were $38(19 \%)$ patients with underlying risk factors. All 12 of the oncology patients had been hospitalized and/or received antibiotics in addition to receiving chemotherapy. One hundred forty-nine children had documented antibiotic exposure in the previous two months (32 penicillins, 38 cephalosporins, three clindamycin, nine other single-agent, 59 multiple and eight not specified). The most frequent indications for antibiotic course were respiratory tract infection (51 of 105), urinary tract infection/prophylaxis (16 of 105), perioperative coverage (11 of 105 ) and other (26 of 105). One hundred eleven children were either inpatients or had been hospitalized within the previous month. Fifty-six were on acid-blocking medications (all had additional risk factors). Only 13 of 200 had none of the selected risk factors indicated in their medical charts.

There were 64 patients younger than one year of age at testing (26 females and 38 males). Three patients $(4.7 \%)$ were special-risk (one with inflammatory bowel disease; two with Hirschsprung disease). Forty patients had documented antibiotic exposure, 19 had none and five had unclear status. Fortysix patients had been hospitalized within the previous month (including birth). Seven infants had none of the selected risk factors.

Disease course characteristics and outcomes are presented in Table 2. The majority of patients (116 [58\%]) were outpatients at symptoms onset. Twenty-seven of these (23\%) required hospitalization due to their symptoms. Seven of 84 inpatients $(8.3 \%)$ had prolongation of stay due to symptoms (written documentation in the medical chart that diarrhea resulted in the delay of planned discharge date). Interestingly, only 25 (12.5\%) had bloody stools; most had nonspecific watery/loose diarrhea. Three patients were transferred to the intensive care unit for closer observation. Of these, one patient underwent exploratory surgery (a five-year-old boy) and one died (a three-year-old girl for whom therapy was withdrawn). Both of these patients had multiple underlying medical problems. A four-month-old male infant presented to the emergency room in cardiorespiratory arrest and could not be resuscitated. Although no stool specimens were collected at the time of death, $\mathrm{C}$ difficile peritonitis and sepsis were 
TABLE 1

Characteristics of $\mathbf{2 0 0}$ children with positive Clostridium difficile cytotoxin

\begin{tabular}{lc}
\hline Category & $\mathbf{n ~ ( \% )}$ \\
\hline Males & $107(53.5)$ \\
Females & $93(46.5)$ \\
Underlying patient risk factor & $38(19.0)$ \\
Chemotherapy & $12(6.0)$ \\
Transplant recipient & $6(3.0)$ \\
Primary immunodeficiency & $7(3.5)$ \\
Inflammatory bowel disease & $7(3.5)$ \\
Hirschsprung disease & $4(2.0)$ \\
Other & $2(1.0)$ \\
Antiacid secretory medications & $56(28.0)$ \\
Ranitidine & $41(20.5)$ \\
Proton pump inhibitor & $13(6.5)$ \\
Proton pump inhibitor + ranitidine & $2(1.0)$ \\
Antibiotic use within prior two months & \\
Yes & $149(74.5)$ \\
No & $35(17.5)$ \\
No documentation in chart & $16(8.0)$ \\
Hospitalization within one month or inpatient for $>48 \mathrm{~h}$ & \\
Yes & $116(58.0)$ \\
No & \\
None documentation available & \\
\hline
\end{tabular}

Findings in the charts of 200 children with $\mathrm{C}$ difficile cytotoxin. Some children had incomplete medical charts: available data are indicated. Please refer to Results section for further details

hypothesized based on autopsy findings and history of $\mathrm{C}$ difficile toxin positivity (one month previously as inpatient and one week previously as outpatient). Hence, the mortality rate in the present study was $1 \%$ (two patients).

In terms of treatment for the $\mathrm{C}$ difficile infection, $55 \%$ of patients $(n=110)$ had documentation of antibiotic treatment with metronidazole initially, the majority for seven to 10 days (with a range of four to 14 days where duration was specified). Of these, 34 (31\%) had recurrence of their symptoms after therapy and required further treatments, including metronidazole, vancomycin, probiotics, cholestyramine and rifampin (Table 2). The most problematic case involved a one-year-old patient with multiple comorbidities and hospitalization for most of his first year of life. He had initially developed $\mathrm{C}$ difficile symptoms shortly after discharge from hospital and subsequently experienced five documented recurrences over a five-month period. He received metronidazole, vancomycin and rifampin and, finally, a prolonged weaning course of vancomycin with eventual symptom resolution. Sixty-eight children (34\%) did not receive pharmacological therapy, the majority having chart documentation of decreased symptoms severity by the time cytotoxin results were available (typically within two to four days).

In 64 patients younger than one year of age, 45 presented with increased watery stools/diarrhea, five with bloody diarrhea and 14 without diarrhea. Only 18 (23\%) had concurrent testing for rotavirus, of which seven were positive. Seven of 28 infants whose symptoms began as outpatients required hospitalization. Five of 36 inpatients had their stay prolonged. Thirty-one $(48 \%)$ had documentation of a course of metronidazole, including three with positive rotavirus results. Five of these $(19 \%)$ were retreated for recurrent/persistent symptoms.
TABLE 2

Disease course and complications in 200 children with Clostridum difficile cytotoxin

\begin{tabular}{lc}
\hline Category & $\mathbf{n}(\%)$ \\
\hline Stool appearance at presentation & \\
Blood in stools (streaks to grossly bloody) & $25(12.5)$ \\
Watery or loose diarrhea (no blood) & $158(79.0)$ \\
No documentation & $17(8.5)$ \\
Initial therapy with metronidazole & \\
Yes & $110(55.0)$ \\
No & $68(34.0)$ \\
No documentation & $22(11.0)$ \\
Serious morbidity and mortality & $4(2.0)$ \\
Intensive care unit observation & $3(1.5)$ \\
Exploratory surgery & $1(0.5)$ \\
Colectomy/bowel removal & 0 \\
Death & $2(1.0)$ \\
Treatment failure interventions* & $34 / 110(31.0)$ \\
Metronidazole & $32(94.0)$ \\
Vancomycin & $5(15.0)$ \\
Probiotic formulation ${ }^{*}$ & $5(15.0)$ \\
Cholestyramine & $2(6.0)$ \\
Rifampin & $1(3.0)$ \\
\hline
\end{tabular}

*Eleven children (32\%) had multiple retreatment measures; ${ }^{\dagger}$ Probiotic formulations included Lactobacillus species in three, VSL\#3 (VSL Pharmaceuticals Inc, USA) in one and not specified in one. Please refer to Results section for further details

\section{DISCUSSION}

In the present study, we describe the characteristics and outcomes of pediatric patients diagnosed with $\mathrm{C}$ difficile infection.

Patient demographics were as expected and sex distribution was fairly evenly split between males and females. The median age of patients (2.6 years) was young and suggests that preschool-aged children are over-represented. This may be because of decreased hygiene in this population, more respiratory illness requiring antibiotic treatment and/or other host factors.

The risk factors selected for inclusion and prevalence were based on published accounts in the literature including recent use of antibiotics (within two months), recent hospitalization, host factors and the use of acid-blocking agents (ranitidine and/or proton pump inhibitors).

The association between recent antibiotic use and finding of $\mathrm{C}$ difficile infection was striking, with $70 \%$ of patients having had received antibiotics in the prior eight weeks. In our population, most antibiotics were prescribed to outpatients. Our frequency of antibiotic use was much higher than in a 1982 study by Boenning et al (26), in which $78 \%$ of pediatric outpatients positive for $\mathrm{C}$ difficile had not been exposed to antibiotics in the prior month. A more recent review (19) also suggested that the majority of pediatric $\mathrm{C}$ difficile was not related to antibiotics. Our high rate of antibiotic exposure may be related to a number of variables, including increased documentation of antibiotic use when children present with diarrheal illness and increased testing for $\mathrm{C}$ difficile when antibiotic use is elicited.

The most important indication for antibiotics was a respiratory tract infection (51 of 105 cases in which the reason for antibiotic course was documented), most notably otitis media (20 of 51). For some children, the indication for antibiotics was not obvious by the clinical data available in their charts, and so our findings may underestimate the actual percentage of 
cases involving respiratory infections. The medical literature lists penicillins and cephalosporins, typical first-line antibiotics for treatment of respiratory tract pathogens, as major culprits in the pathogenesis of $\mathrm{C}$ difficile. Our study findings agree with this, with penicillins and cephalosporins accounting for $23 \%$ and $27 \%$ of antibiotic type when specified, respectively. Because many respiratory tract infections are viral in origin, this may indicate roles for both close vigilance in prescribing antibiotics as well as monitoring of symptom progression in otherwise-well children before an antibiotic course is considered. Clindamycin was prescribed to only three of 141 patients.

A high number of patients (111 of 200 [55.5\%]) had been hospitalized within the time-frame described for nosocomial acquisition. Nosocomial infection likely occurs not only due to host susceptibility factors, but also as a consequence of multiple contaminated environmental surfaces within hospital settings, improperly washed personnel hands, shared medical instrumentation, infected roommates and persisting spores $(1,4)$.

A review of the literature of at-risk patient populations revealed some debate as to whether being part of a special population acts as an independent risk factor for $\mathrm{C}$ difficile acquisition, or whether being a 'special population' patient represents a confounder in sick hospitalized (adult) patients. In fact, compared with adult $\mathrm{C}$ difficile patients, who commonly have special risks, there were only $19 \%$ of patients who fit into a vulnerable patient population.

Methotrexate, fluorouracil, etoposide, mitoxantrone, paclitaxel and other chemotherapeutic agents have been associated with $\mathrm{C}$ difficile infection due to their effects on bowel flora and associated inflammation (27-31). One prospective study of pediatric oncology patients did not find $\mathrm{C}$ difficile to be an important pathogen, nor did it find an association with use of antibiotics and/or chemotherapy, although 19\% of asymptomatic inpatients harbored toxigenic $C$ difficile (16). In the present study, none of the 12 oncology patients had been exclusively on chemotherapeutic medication; all had additional risk factors (hospitalization, antibiotic exposure, etc).

Solid organ transplant recipients represent an important fraction of $\mathrm{C}$ difficile patients, likely related to significant immunosuppression, prolonged hospitalization and frequent use of antibiotics. A study by West et al (21) revealed that $16 \%$ (43 of 267) of pediatric renal transplant recipients developed $\mathrm{C}$ difficile colitis, at a mean time of 33 days after transplantation. In the present series, six (3\%) of our patients were renal transplant recipients. Of these, five were diagnosed within the first postoperative month, while one had been grafted three years prior.

Abnormal intestinal environments that result in altered motility, stasis and an abnormal mucin barrier, such as in inflammatory bowel disease and Hirschsprung disease, may predispose to more severe disease $(32,33)$. The present series included seven patients with Crohn's disease and four with Hirschsprung disease: whether this disproportionate number is due to a real increase in risk or due to increased frequency of testing in these patients (asymptomatic carriage being identified) is unclear. None of these patients necessitated endoscopic evaluation.

There is a high rate of recurrent $\mathrm{C}$ difficile disease in patients with hypogammaglobulinemia, perhaps related to an inability to produce antibodies to the toxins. The ability to produce sufficient immunoglobulin $\mathrm{G}$ directed against cytotoxin $\mathrm{A}$ has been shown to be an important protective response in adults (34).
Other primary immunodeficiencies may also affect the intestinal environment or the host's ability to respond to $\mathrm{C}$ difficile. Seven of our 200 patients had an immunodeficiency, including severe combined immunodeficiency, hypogammaglobulinemia, Chediak-Higashi syndrome, T cell defects or an absent thymus.

Recent reports have suggested an association between reduced gastric acidity with increased risk for $\mathrm{C}$ difficile $(7,8)$. Fifty-six (28\%) children had an exposure to ranitidine and/or proton pump inhibitors at the time of presentation. Whether this high proportion reflects a true etiological link in children or whether it simply reflects a group of children who had an overall high exposure to the health care system and medications cannot be determined in this descriptive study. With the recent increase in pediatric proton pump inhibitor use, further study into a possible link may be indicated.

A high baseline rate of pediatric $\mathrm{C}$ difficile carriage may explain why a proportion of patients had spontaneous symptoms resolution. Because many children were not tested for alternative pathogens (eg, rotavirus) this possibility cannot be verified or excluded. Alternatively, recovery without therapy may illustrate the capacity of otherwise-well children to control $\mathrm{C}$ difficile in the absence of antibiotics. In fact, the necessity of treating a positive $\mathrm{C}$ difficile result may be questioned for certain populations, especially well infants younger than one year of age, where the carriage rate is highest and frequency of symptomatic disease is low, possibly due to poor binding of toxins to immature colonic mucosal binding sites. In the present study, our results showed a trend toward children older than one year of age being treated more frequently. However, there remained a significant number of infants being tested for $\mathrm{C}$ difficile $32 \%$ of the total group were younger than one year of age) and a large proportion of these being prescribed metronidazole without having eliminated alternate pathogens in diarrheal etiology (only 28\% were tested for rotavirus).

The complication rate and degree of severity of pediatric $\mathrm{C}$ difficile in this pediatric group was less than in a series of adults admitted with $\mathrm{C}$ difficile colitis, with $24 \%$ and $15.3 \%$ mortality rates in series by Morris et al (5) and Ramaswamy et al (35), respectively. A recent case-control series by Dial et al (8) of 94 patients reported that $22 \%$ of patients infected with $\mathrm{C}$ difficile died compared with $14 \%$ of matched controls. Additionally, 19\% were admitted to intensive care and 9\% required colectomy. In our present series, only three children required admission to an intensive care unit. There was one exploratory laparotomy and two deaths from sepsis.

The percentage of children requiring a second (or subsequent) antibiotic course was $31 \%$. This value is similar to the $15 \%$ to $35 \%$ range reported in the adult literature (6). Although recurrences tended to be mild, one patient required five separate treatments before final clinical improvement.

The present study was descriptive in nature and the findings are limited by information documented in the child's medical record. This lack of data may have underestimated the presence of risk factors (such as antibiotic use within the previous two months).

\section{CONCLUSIONS}

The present study describes a population of 200 Canadian children with $\mathrm{C}$ difficile infection. A large majority of pediatric patients diagnosed with $\mathrm{C}$ difficile have antibiotic exposure within the previous two months or hospitalization within the 
previous month. This is higher than in previously reported pediatric series. Importantly, these represent potentially modifiable risk factors. Many children have a mild illness course, which can be managed in an outpatient setting. However, $23 \%$ of outpatients required hospitalization, while $8.3 \%$ of inpatients required prolongation of stay for symptom management. One-third of the children had spontaneous symptoms resolution. For those treated, recurrence rates were high but similar to that reported in adult studies. Significant morbidity was rare: intensive care was necessary in only a few and surgical exploration without colectomy in one. Mortality attributable to $\mathrm{C}$ difficile was $1 \%$. Hence, for this pediatric population, C difficile-associated diarrhea was linked to favourable outcomes. This result is a striking contrast to adult cohorts, which have documented steady increases of morbidity and mortality in recent years.

\section{REFERENCES}

1. Barbut F, Petit JC. Epidemiology of Clostridium difficile-associated infections. Clin Microbiol Infect 2001;7:405-10.

2. Buchner AM, Sonnenberg A. Medical diagnoses and procedures associated with Clostridium difficile colitis. Am J Gastroenterol 2001;96:766-72.

3. Djuretic F, Wall PG, Brazier JS. Clostridium difficile: An update on its epidemiology and role in hospital outbreaks in England and Wales. J Hosp Infect 1999;41:213-8.

4. Kyne L, Farrell RJ, Kelly CP. Clostridium difficile. Gastroenterol Clin North Am 2001;30:753-77.

5. Morris AM, Jobe BA, Stoney M, Sheppard BC, Deveney CW, Deveney KE. Clostridium difficile colitis: An increasingly aggressive iatrogenic disease? Arch Surg 2002;137:1096-100.

6. Fekety R. Guidelines for the diagnosis and management of Clostridium difficile-associated diarrhea and colitis. American College of Gastroenterology, Practice Parameters Committee. Am J Gastroenterol 1997;92:739-50.

7. Cunningham R, Dale B, Undy B, Gaunt N. Proton pump inhibitors as a risk factor for Clostridium difficile diarrhoea. J Hosp Infect 2003;54:243-5.

8. Dial S, Alrasadi K, Manoukian C, Huang A, Menzies D. Risk of Clostridium difficile diarrhea in hospital in-patients prescribed proton pump inhibitors: Cohort and case-control studies. CMAJ 2004;171:33-8.

9. Elmer GW, McFarland LV. Biotherapeutic agents in the treatment of infectious diarrhea. Gastroenterol Clin North Am 2001;30:837-54.

10. Leung DY, Kelly CP, Boguniewicz M, Pothoulakis C, LaMont JT, Flores A. Treatment with intravenously administered gamma globulin of chronic relapsing colitis induced by Clostridium difficile toxin. J Pediatr 1991;118:633-7.

11. Liacouras CA, Piccoli DA. Whole-bowel irrigation as an adjunct to the treatment of chronic, relapsing Clostridium difficile colitis. J Clin Gastroenterol 1996;22:186-9.

12. McFarland LV, Surawicz CM, Greenberg RN, et al. A randomized placebo-controlled trial of Saccharomyces boulardii in combination with standard antibiotics for Clostridium difficile disease. JAMA 1994:271:1913-8.

13. McFarland LV, Elmer GW, Surawicz CM. Breaking the cycle: Treatment strategies for 163 cases of recurrent Clostridium difficile disease. Am J Gastroenterol 2002;97:1769-75.

14. Salcedo J, Keates S, Pothoulakis C, et al. Intravenous immunoglobulin therapy for severe Clostridium difficile colitis. Gut 1997;41:366-70.
15. Schwan A, Sjolins, Trottestam V, Aronsson B. Relapsing Clostridium difficile enterocolitis cured by rectal infusion of normal feces. Scand J Infect Dis 1984;16:211-5.

16. Burgner D, Siarakas S, Eagles G, McCarthy A, Bradbury R, Stevens M. A prospective study of Clostridium difficile infection and colonization in pediatric oncology patients. Pediatr Infect Dis J 1997;16:1131-4.

17. Canadian Paediatric Society Infectious Diseases and Immunization Committee. Clostridium difficile - Pathogen or pest? Paediatr Child Health 2000;5:349-52.

18. Cerquetti M, Luzzi I, Caprioli A, Sebastianelli A, Mastrantonio P. Role of Clostridium difficile in childhood diarrhea. Pediatr Infect Dis J 1995;14:598-603.

19. McFarland LV, Brandmarker SA, Guandalini S. Pediatric Clostridium difficile: A phantom menace or clinical reality? J Pediatr Gastroenterol Nutr 2000;31:220-31.

20. Thompson CM, Gilligan PH, Fisher MC, Long SS. Clostridium difficile cytotoxin in a pediatric population. Am J Dis Child 1983;137:271-4.

21. West M, Pirenne J, Chavers B, et al. Clostridium difficile colitis after kidney and kidney-pancreas transplantation. Clin Transplant 1999;13:318-23.

22. Wolfhagen MJ, Meijer K, Fluit AC, et al. Clinical significance of Clostridium difficile and its toxins in faeces of immunocompromized children. Gut 1994;35:1608-12.

23. Enad D, Meislich D, Brodsky NL, Hurt H. Is Clostridium difficile a pathogen in the newborn intensive care unit? A prospective evaluation. J Perinatol 1997;17:355-9.

24. Larson HE, Barclay FE, Honour P, Hill ID. Epidemiology of Clostridium difficile in infants. J Infect Dis 1982;146:727-33.

25. Tullus K, Aronsson B, Marcus S, Mollby R. Intestinal colonization with Clostridium difficile in infants up to 18 months of age. Eur J Clin Microbiol Infect Dis 1989;8:390-3.

26. Boenning DA, Fleisher GR, Campos JM, Hulkower CW, Quinlan RW. Clostridium difficile in a pediatric outpatient population. Pediatr Infect Dis 1982;1:336-8.

27. Anand A, Glatt AE. Clostridium difficile infection associated with antineoplastic chemotherapy: A review. Clin Infect Dis 1993;17:109-13.

28. Blot E, Escande MC, Besson D, et al. Outbreak of Clostridium difficile-related diarrhoea in an adult oncology unit: Risk factors and microbiological characteristics. J Hosp Infect 2003;53:187-92.

29. Husain A, Aptaker L, Spriggs DR, Barakat RR. Gastrointestinal toxicity and Clostridium difficile diarrhea in patients treated with paclitaxel-containing chemotherapy regimens. Gynecol Oncol 1998; 71:104-7.

30. Jarvis B, Shevchuk YM. Recurrent Clostridium difficile diarrhea associated with mitoxantrone and etoposide: A case report and review. Pharmacotherapy 1997;17:606-11.

31. Tomblyn M, Gordon L, Singhai S, et al. Rarity of toxigenic Clostridium difficile infections after hematopoietic stem cell transplantation: Implications for symptomatic management of diarrhea. Bone Marrow Transplant 2002;30:517-9.

32. Qualman SJ, Petric M, Karmali MA, Smith CR, Hamilton SR. Clostridium difficile invasion and toxin circulation in fatal pediatric pseudomembranous colitis. Am J Clin Pathol 1990;94:410-6.

33. Kindon H, Pothoulakis C, Thim L, Lynch-Devaney K, Podolsky DK. Trefoil peptide protection of intestinal epithelial barrier function: Cooperative interaction with mucin glycoprotein. Gastroenterology 1995; 109:516-23.

34. Kyne L, Warny M, Qamar A, Kelly CP. Asymptomatic carriage of Clostridium difficile and serum levels of IgG antibody against toxin A. N Engl J Med 2000;342:390-7.

35. Ramaswamy R, Grover H, Corpuz M, Daniels P, Pitchumoni CS. Prognostic criteria in Clostridium difficile colitis. Am J Gastroenterol 1996;91:460-4. 


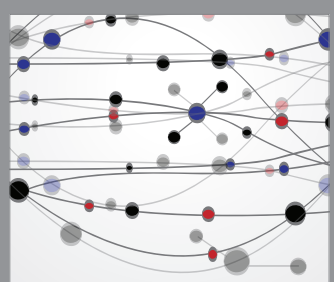

The Scientific World Journal
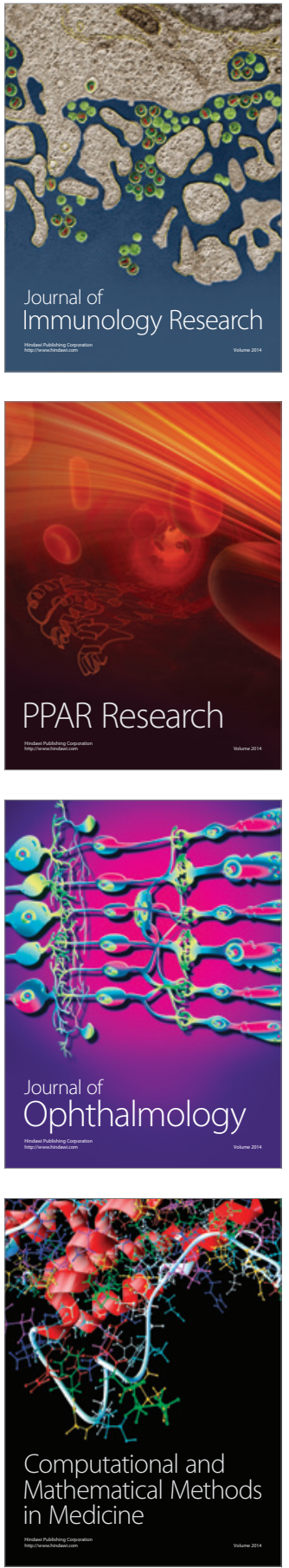

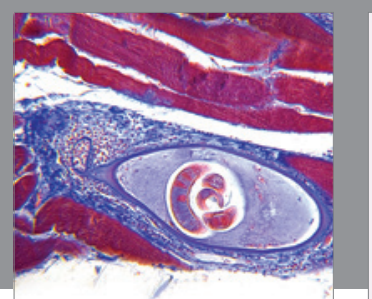

Gastroenterology Research and Practice

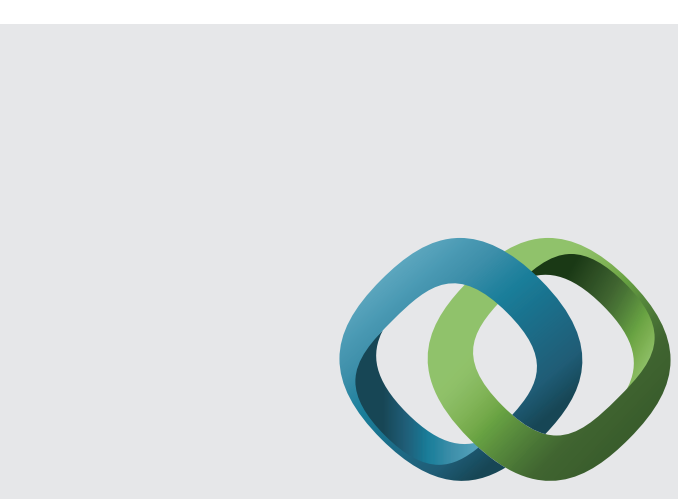

\section{Hindawi}

Submit your manuscripts at

http://www.hindawi.com
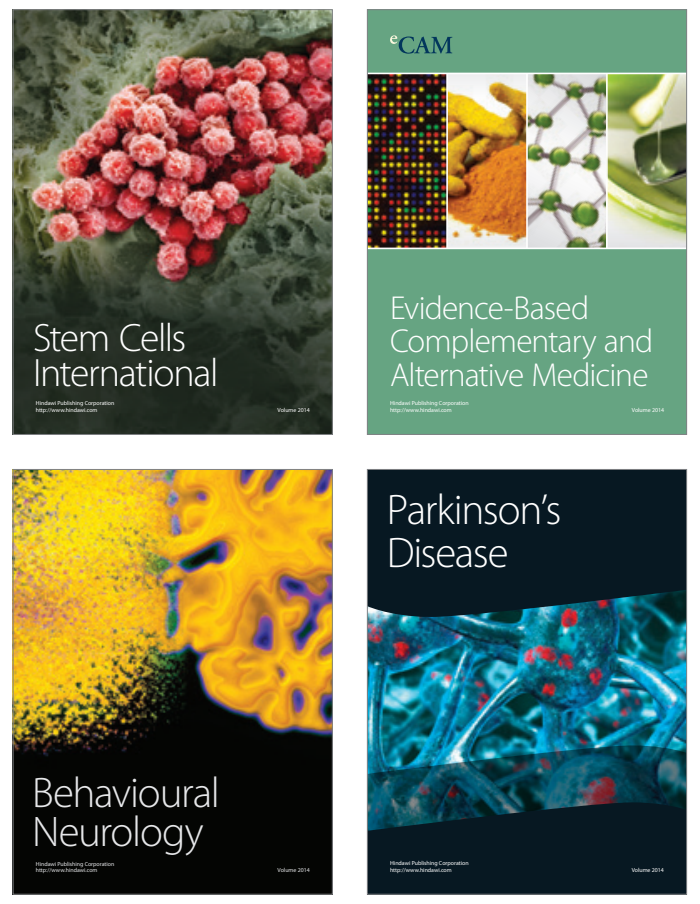
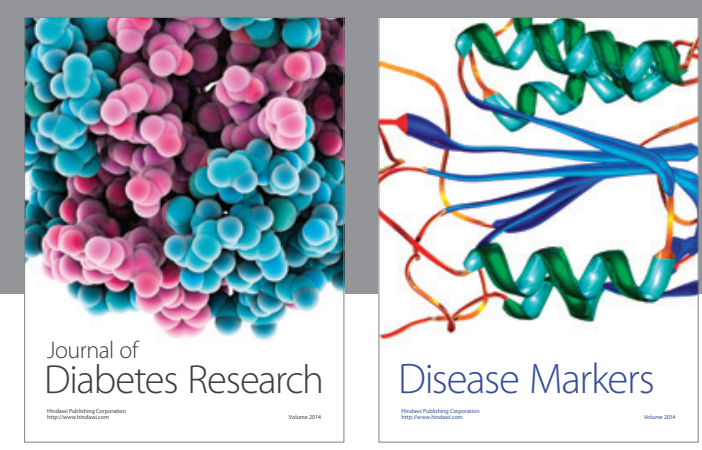

Disease Markers
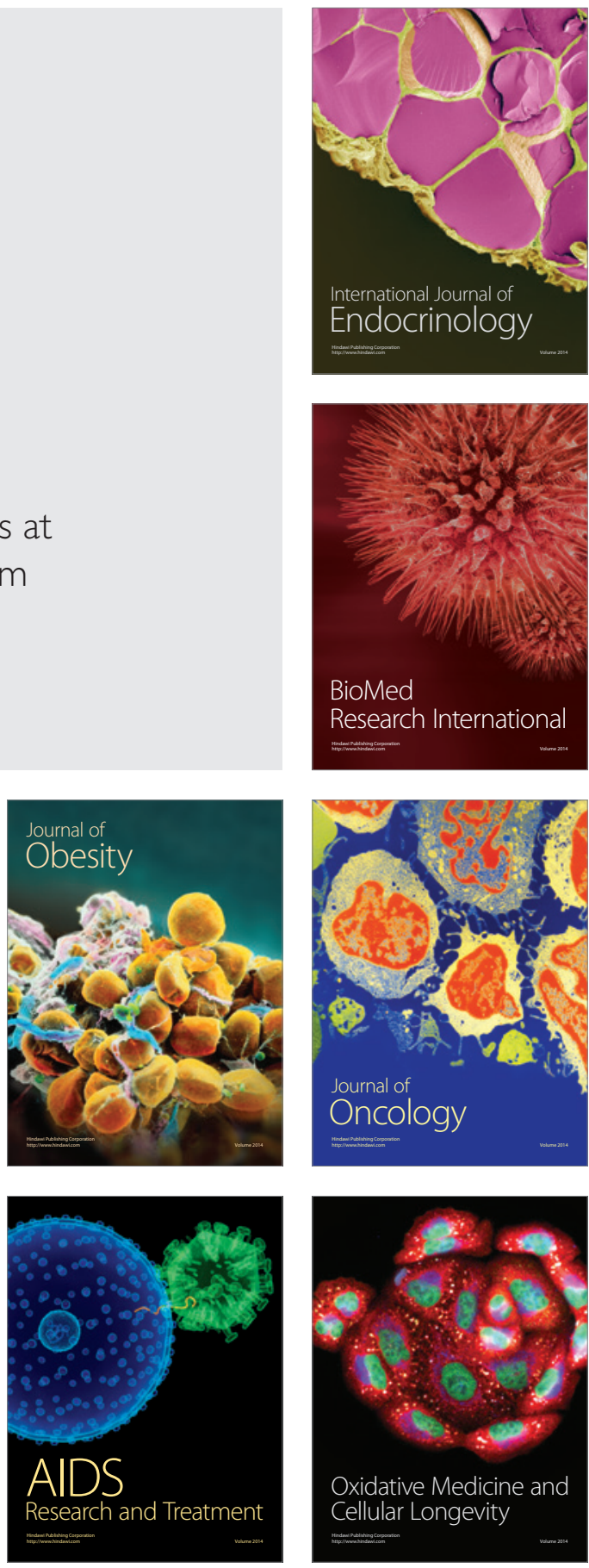